\title{
As influências de uma parceria entre leitor e escrito na produção de textos
}

\author{
The partnership influences between reader and \\ writer in texts production
}

\section{L'influence d'un partenariat entre le lecteur et l'écrivain à la production de textes}

\author{
Poliana BRUNO ZUIM
}

Claudia Raimundo REYS

\begin{abstract}
RESUMO
Este artigo tem como finalidade apresentar os resultados de uma pesquisa realizada, em que se procurou verificar a formação da consciệncia discursiva em alunos pertencentes a uma segunda série do ensino fundamental. Tal pesquisa busca contribuir metodologicamente para área de processos de ensino-aprendizagem da língua materna, salientando como a mediação intencional, propiciada pelas condições de produção, contribui para a formação da consciência discursiva dos produtores de textos por meio de uma parceria entre leitor e escritor.
\end{abstract}

Palavras-chave: produção de texto, leitor e escritor, mediação, parceria.

\section{ABSTRACT}

This article aims to present a research, whose goal was to verify the formation of consciousness discourse on producers of texts, seeking help methodologically for the area of teaching-learning processes of the mother tongue. Look like intentional mediation offered by the conditions of production contributes to the formation of consciousness discourse of the producers of texts through a partnership between reader and writer. partnership.

Index terms: production of text, reader and writer, mediation, 


\section{RÉSUMÉ}

Cet article a pour but de présenter les résultats d'une recherche, dans laquelle nous avons vérifié la formation de la conscience discursive des élèves de la deuxième année de l'enseignement primaire. Cette recherche vise à contribuer méthodologiquement dans l'espace enseignementapprentissage de la langue maternelle, mettant en évidence la médiation intentionnelle, propice aux conditions de production, à contribuer dans la formation de la conscience discursive des producteurs de textes par le moyen d'une parité entre le lecteur et l'auteur.

Mots- clés: production de texte, lecteur et auteur, médiation, parité.

\section{Introdução}

Muitos são os trabalhos na área do ensino da língua que abordam a questão da produção textual. $\mathrm{O}$ enfoque neste tema específico deveu-se às significativas mudanças na maneira de se compreender a língua.

Desde a década de 80 , a produção textual passou a ser um dos apontamentos metodológicos para a mudança nos processos de ensinoaprendizagem da língua. Mas, como trabalhar a produção de textos em salá de aula? Que aspectos da língua deve o professor considerar em sua avaliação quando se trata de produção textual? Apesar das diretrizes curriculares-contidas nas políticas públicas para-ensino da língua, essas continuam sendo algumas das indagações de muitos professores. Pensando numa forma de poder contribuir com a área de processos de ensinoaprendizagem da língua, desenvolvemos uma pesquisa utilizando uma metodologia interventiva, em que, por meio de situações planejadas, procurou-se tornar mais significativa a aprendizagem escrita das crianças do ensino fundamental. Para tanto, buscamos verificar, identificar e analisar os conhecimentos sobre a língua gerados por meio de uma de parceria entre leitor e escritor, tendo em vista a formação de um escritor consciente do discurso produzido. 
Nesse sentido, o quadro teórico que fundamenta essa pesquisa está composto pela articulação entre a teoria Histórico- cultural e a concepção de linguagem vista como um processo de interação, também chamada de Linguística da Enunciação de Bakhtin. Essas duas correntes teóricas, ainda que em campos distintos (Psicologia e Linguística), possuem a mesma concepção de sujeito e vêem a linguagem como principal mediadora e constituídoras dos indivíduos e da consciência.

\section{Referencial teórico}

\subsection{Vygotsky e Bakhtin: ensino- aprendizagem da língua}

Vygotsky e Bakhtin são dois autores importantes na área da linguagem. Eram russos e produziram suas teorias no início do século passado (séc. XX), a fim de criar uma Psicologia e uma Teoria da Linguagem que considerasse os pressupostos filosóficos do novo sistema político e econômico que se implantara na antiga União Soviética - URSS, o regime socialista. Dessa forma, os pressupostos filosóficos que orientam a teoria desses autores é o materialismo-histórico de Karl Marx. Nessé sentido, algumas categorias do materialismo são essenciais nas teorias desses autores. Entre elas, destaca-se a categoria de Mediação.

A categoria de mediação é de fundamental relevância para o materialismo-histórico, pois é nas relações sociais que se constitui o sujeito. Dessa forma, o social possui um valor precípuo, pois a constituição do indivíduo ocorre por meio das mediações, sejam elas intencionais ou não. Segundo esse pressuposto filosófico, o indivíduo se constrói no contexto social em que vive e é através da interação com os outros que ele tem contato com instrumentos físicos e simbólicos que nortearão o seu pensamento e a sua vida em sociedade.

Conforme a teoria marxista, a categoria de mediação é inerente ao trabalho e foi por meio dele que se complexificou modificando não só o 
meio social, mas o próprio homem. Marx refere-se à mediação através do uso de instrumentos aplicados à atividade do trabalho, Vygotsky e Bakhtin atentam para a importância da mediação sígnica. O destaque desses teóricos à mediação por meio dos signos refere-se, sobretudo a complexificação da sociedade, tal como nos descreve Araújo (2000). Segundo os teóricos em questão, os signos é o que constitui a consciência. Entretanto, Bakhtin enfatiza o aspecto ideológico existente neles, já Vygotsky ressalta a importância dos mesmos na mediação dos processos mentais superiores.

Vygotsky (1995) descreve dois tipos de atividades mediadoras: os instrumentos e os signos. A mediação por instrumentos, afirma, possui ligação direta com os postulados marxistas a respeito de sua importância como elemento interposto entre o trabalhador e o objeto de seu trabalh $\phi$, ou seja, o instrumento é feito com o intuito de um objetivo específico é, pois, um objeto social e mediador da relação do homem com o mundô. Já a mediação por signos é outro meio inventado pela humanidade a fim de auxiliá-la no campo psicológico. O signo age como mediador psicológico de maneira similar ao uso dos instrumentos no trabalho, porém o que os diferencia é que os instrumentos são externos aos indivíduos cuja função é provocar mudanças nos objetos; os signos, por sua vez, são orientados para o próprio sujeito, de modo a auxiliar os processos psicológiços de fora para dentro e podem referir-se a elementos ausentes no espaço e tempo presentes. De acordo com o autor, a memória mediada por signos é mais poderosa que a memória não mediada, pois o uso de mediadores aumenta a capacidade de atenção e de memória. Assim, o processo de mediação, por meio de signos, é fundamental para o desenvolvimento das funções psicológicas superiores, isto é, a relação entre o pensamento e a linguagem.

$\mathrm{Na}$ definição de Bakhtin (1995), o signo é um objeto físico pertencente a uma determinada realidade, mas que, por ser ideológico, reflete e refrata outra que lhe é exterior. Como ele reflete e refrata outra realidade, ele pode distorcê-la, por isso, todo signo é ideológico. Para 
explicar a "refração" da realidade, o autor nos incita a pensarmos como os signos são utilizados pelos diversos campos ideológicos.

Cada área do saber utiliza os signos de acordo com a sua realidade, refratando esta a sua própria maneira, todavia é seu caráter semiótico, isto é, os significados/conceitos/generalizações, que coloca todos os fenômenos ideológicos sob a mesma definição geral.

De acordo com Bakhtin (1995), os signos só emergem a partir do processo de interação social, assim como a consciência só se torna consciência quando se impregna de conteúdo ideológico no processo dessa interação. Assim, a ideologia reside no material social particular de signos criados pelo homem.

Conforme Bakhtin (2003), toda atividade humana é mediada pelo uso da linguagem. Nesse sentido, esclarece Vygotsky (1995) que as formas de mediação sígnica e suas transformações associadas à vida sócial e psicológica influenciaram decisivamente o desenvolvimento do homem. $\mathrm{Na}$ concepção da história dos signos como mecanismos mnemotécnicos, assim como a sua explicação entre o pensamento e a linguagem, alude Wertsch (1995), Vygotsky concebeu um princípio de desenvolvimento que denominou como princípio de descontextualização dos instrumentes de mediação._A descontextualização de tais instrumentos é o processo mediante o qual o significado dos signos se volta cada vez menos dependente do contexto espaço-tempo em que são utilizados. A pesquisa realizada por Luria (1991) no Uzbequistão evidenciou tal fato. Essa pesquisa analisava a categorização de objetos por sujeitos alfabetizados e analfabetos. Os sujeitos alfabetizados responderam que o martelo, a faca e a serra deveriam estar juntos porque ambos eram ferramentas. Ou seja, eles agruparam os objetos segundo um critério baseado no significado abstrato das palavras. Já os sujeitos analfabetos indicavam uma forte tendência a agrupar os objetos ao contexto de sua finalidade/utilização. Por exemplo, serrote e madeira. 
Nesse sentido, Wertsch (1995) remete-se ao trabalho desenvolvido por Scrbner e Cole (1981) que evidencia que o importante não é sabermos codificar e decodificar símbolos gráficos, mas, sim, como utilizamos essa alfabetização que governa a descontextualização e suas possíveis consequências sobre o funcionamento das funções psíquicas superiores.

Essa é uma questão que tem remetido a várias inquietações a nós e aos pesquisadores que também trabalham com os processos de ensinoaprendizagem da língua desde a alfabetização. Em termos de atividade de leitura e produção textual essa questão é muito evidente, uma vez que muitos de nossos alunos decodificam e codificam a língua, mas não conseguem compreender o sentido do texto que lêem. Portanto, não são capazes de estabelecer relações das leituras realizadas com a vida cotidiana, isto é, a leitura do mundo e a leitura da palavra acontecem num processo dicotômico, como bem salienta Freire (1990).

Foi pensando nessa problemática, na questão da contextualizaçã̉o e descontextualização da linguagem e a formação da consciência, do sujeito, que nos inquietamos com a questão da formação da consciência discursiva entre leitores e produtores de textos, já que a atividade escrita é um processo totalmente dialético. Dialético, porque ao mesmo tempo em que a_escrita é uma atividade descontextualizada em nível de pensamento, ela necessita o tempo todo da contextualização para dar significado a sua enunciação.

\subsection{Linguagem, sujeito e consciência}

É por meio da linguagem, que conseguimos pensar e tomar conhecimento sobre a história da humanidade, por meio dela os homens puderam expressar os seus pensamentos, interagirem uns com os outros, criando assim a cultura. Dissociar a linguagem do pensamento é refutar que os homens vivem em sociedade e dependentes uns dos outros, pois somente por meio dessa necessidade de se interagir que denominamos tudo o que 
denominamos, que significamos a nós mesmos e tudo o que é exterior a nós. Dissociar a linguagem do pensamento é refutarmos a nossa própria existência, a nossa condição humana de sujeitos pensantes e históricos (BRUNO, 2006).

No processo de interação do bebê com o seu meio, em certo momento de seu desenvolvimento, tal como bem evidenciou Vygotsky (1993), a palavra acaba por constituir e iluminar o seu pensamento. Isto posto, a apreensão do mundo sensível ocorre sobre a forma de linguagem, seja a linguagem gestual, oral ou escrita. A apreensão do mundo sensível num nível mais abstrato se dá explicitamente pela palavra, uma vez que os conceitos resumem um encadeamento de palavras e categorização do mundo objetivo por meio de e através das palavras.

Quando nos referendamos aos processos de ensino-aprendizagem de qualquer disciplina e área específica, discursamos sempre dentro de uma concepção teórica que nos fundamenta como sujeitos. Não poderia ser diferente no caso do ensino da língua. A linguagem como constituídora do homem e da sua consciência destaca-se na teoria aqui adotada. Ela quem permite interagirmos com o mundo.

Tanto Vygotsky quanto Bakhtin enfatizam a consciência_e a sua formação como um conceito fundamental para o entendimento das específicas teorias. Na filosofia marxista-leninista o conceito de consciência é tão importante como o de matéria. O problema da origem e da essência da consciência é crucial em todas as doutrinas e teorias filosóficas, graças à consciência é possível avaliar os acontecimentos e os outros homens, compreender o mundo e analisar o conhecimento historicamente construído.

Na busca da sobrevivência e a necessidade de empregar instrumentos para suprir as necessidades básicas iniciou-se nos nossos antepassados a transformação dos reflexos em atividade consciente suscetível de transformar o meio ambiente com instrumentos especialmente preparados. Foi justamente o trabalho que conferiu ao corpo e ao cérebro, o mecanismo 
de sensações em geral, características humanas. Portanto, o novo tipo de atividade - a produção - e o novo tipo de relações - as relações de produção - conduziram mudanças qualitativas na percepção do meio ambiente. Além disso, desenvolveu-se no homem a faculdade específica de determinar conscientemente um objetivo. Assim, a conscientização do ambiente, a identidade de si próprio enquanto indivíduo e a atividade subordinada a um fim constituem os três atributos do reflexo da realidade que surgiu durante a evolução do homem.

A linguagem também foi produto da necessidade dos homens de se relacionarem uns com os outros. Com ela, afirma Krapivine (1986), o homem começou a designar fenômenos, propriedades, objetos e ações com certos sons e sinais no intuito de se comunicar. O reflexo da realidade através das palavras é a forma especificamente humana.

Marx (1977) afirma que a consciência é, antes de tudo, a consciência do meio sensível imediato e de uma relação limitada com outras pessoas e outras coisas situadas fora do indivíduo que toma consciência. Conclui-se que a consciência surgiu das necessidades da produção e da vida social em geral, por isso, ela não pode aparecer nem existir fora da sociedade e das relações sociais.

Nesse sentido Bakhtin (1995), fundamentado em Marx, afirma que a consciência só se torna consciência quando se impregna de conteúdo ideológico, enfatizando que isso só ocorre no processo de interação social. Desta forma, tanto ele quanto Vygotsky enfatizam a importância dos signos, ou seja, da linguagem na constituição da consciência - na formação do sujeito.

Descreve Bakhtin que "a consciência individual não só pode se explicar, mas, ao contrário, deve ela própria ser explicada a partir do meio ideológico e social" (BAKHTIN, 1995, p.35).

De acordo com Bakhtin (2003), toda atividade humana é mediada pelo uso da linguagem. Todavia, as formas e o uso da linguagem se diferem 
de acordo os vários tipos de atividade humana, ainda que todas essas formas e usos façam parte da unidade nacional de uma língua. $\mathrm{O}$ autor alude à neutralidade da palavra que corresponde à significação e à ausência do conteúdo ideológico dado nos diferentes campos da atividade do homem.

Nesse sentido, esclarece Vygotsky (1930) que as formas de mediação sígnica e suas transformações associadas à vida social e psicológica influenciaram decisivamente o desenvolvimento do homem, não podendo resolver o problema do animal-humano apenas sob a ótica da teoria da evolução. Segundo este autor, o emprego de ferramentas psicológicas proporcionou as bases para o trabalho organizado. Desta forma, tal como propôs Marx, o trabalho é o fator básico de transformação dos símios seres humanos.

A fim de traçar as diferenciações dos signos criados pelo homem no seu processo histórico apresentaremos, a seguir, as diferenciações éntre a linguagem oral e a escrita, definidas por Vygotsky.

\subsection{Linguagem oral e linguagem escrita}

A teoria psicológica de Vygotsky (1993) distinguiu as diferentes funções da linguagem, se atendo as diferenças entre a oralidade- $\bar{c}$ escrita. Analisando-essas duas atividades, Vygotsky (ibidem) expliea que o gesto é o início do processo tanto da fala como da escrita. Todavia, essas atividades se distinguem pelo fato de uma necessitar do contexto e a outra precisar de uma gama maior de palavras e significados. Segundo o autor, a oralidade tem a possibilidade de expressão imediata e não premeditada, já a escrita, exige um esforço consciente e intencional. Desta forma, a linguagem escrita necessita da linguagem interna para expressar o pensamento, portanto, faz o uso das normas do significado estrito da palavra, diferentemente da linguagem oral. 
Conforme explicitado, o pensamento não só está mediado externamente por signos, como internamente por seus significados, isto é, o caminho do pensamento à palavra é um caminho indireto e mediado internamente. Segundo o autor, "a linguagem escrita é uma função lingüística distinta que difere da linguagem oral tanto pela sua estrutura quanto pela sua função" (VYGOTSKY, 2001, p.131).

Vygotsky (1991) salienta que a linguagem escrita é formada por um sistema de signos que identifica os sons e as palavras da linguagem oral, que são signos de objetos e relações sociais. A linguagem oral, explica o autor, pode extinguir-se gradualmente, já a escrita pode transformar-se em um sistema de signos que simbolizam os objetos designados, assim como as suas relações recíprocas. A linguagem escrita permite a comunicação além do tempo, daí a sua função como mediadora da cultura para a apropriação pelos sujeitos. Por tal razão, a escrita é um signo construído historicámente para mediar e registrar as produções da humanidade além do tempo presente.

A palavra escrita é um dos aspectos do desenvolvimento individual e cultural dos sujeitos e está relacionada com o domínio do sistema externo de meios elaborados e estruturados no processo de evolução culturał da humanidade, ela pertence à primeira e mais evidente linha do desenvolvimento cultural, daí a aprendizagem da palavra escrita não ocorrer por evolução, mas sim, através de um movimento progressivo que se inicia com o brincar. $\mathrm{O}$ autor diz que a linha do desenvolvimento da escrita é uma linha descontínua, contrapondo à visão ingênua de que o desenvolvimento é um processo puramente evolutivo.

Diferentemente da linguagem oral, na qual a criança pode desenvolver por si mesma, a linguagem escrita depende de um trabalho intencional requerendo atenção e esforços por parte do professor e do aluno. Portanto, o referido autor procura revelar essa pré-história da linguagem escrita, mostrando o que leva a criança a escrever, evidenciando assim, os 
principais pontos pelos quais passa esse desenvolvimento pré-histórico, assim como a sua relação com o aprendizado escolar.

Segundo Vygotsky (2001), essa história inicia-se com o aparecimento do gesto como um signo visual para a criança. Os gestos são a escrita no ar, e os signos escritos são, simples gestos que foram fixados. Conforme o autor, existem dois domínios onde os gestos estão ligados à origem dos signos escritos. O primeiro é o dos rabiscos das crianças; o segundo que liga os gestos à linguagem escrita são os jogos das crianças.

Assim, o brinquedo simbólico das crianças pode ser entendido como um sistema muito complexo de "fala". Por meio de gestos indicativos que, na brincadeira, os objetos passam a adquirir, gradualmente, significadós assim como o desenho que, de início apoiado por gestos, transforma-sé em signo independente. O objeto adquire uma função de signo, tornando-se, nessa fase, independente dos gestos das crianças. Vygotsky (2001) considera a brincadeira do faz-de-conta como um dos grandes contribuídores para o desenvolvimento da linguagem escrita - que é um sistema de simbolismo de segunda ordem.

Assim como no brinquedo, também no desenho, o significado surge, inicialmente, como um simbolismo de primeira ordem. Os primeíros desenhos surgem como resultado de gestos manuais; o gesto constitui a primeira representação do significado. É somente mais tarde que a representação gráfica começa a designar algum objeto.

Vygotsky (2001), considerando a pesquisa de Luria, afirma que gradualmente as crianças transformam esses traços indiferenciados em pequenas figuras e desenhos, e estes, por sua vez, são substituídos pelos signos. É claro que os sinais escritos constituem símbolos de primeira ordem, denotando diretamente objetos ou ações e que a criança terá ainda que evoluir no sentido do simbolismo de segunda ordem, que compreende a criação de sinais escritos representativos dos símbolos falados das palavras. Para isso, a criança precisa fazer uma descoberta básica - a de que se pode 
desenhar, além de coisas, também a fala. Foi essa descoberta, ressalta o autor, que levou a humanidade ao método da escrita por palavras e orações; a mesma descoberta conduz as crianças à escrita literal.

Do ponto de vista pedagógico, essa transição deve ser propiciada pelo deslocamento da atividade da criança do desenhar coisas para o desenhar a fala. Vygotsky (2001) salienta que o segredo do ensino da linguagem escrita é preparar e organizar adequadamente essa transição de forma natural; uma vez que ela é atingida, a criança passa a dominar o princípio da linguagem escrita, restando a ela, aperfeiçoar esse método.

Segundo o autor, tudo isso leva a crer que o processo de desenvolvimento da linguagem escrita se desenvolve a partir de uma linha histórica unificada que conduz às formas superiores da linguagem escrita. Ou seja, é necessário que o professor compreenda que o processo de apropriação da escrita é um processo unificado, composto por um cónjunto de aprendizagens necessárias para a criança escrever segundo as normas estabelecidas socialmente. A escrita deve ser ensinada como uma atividade social complexa, portanto, necessita que o seu ensino seja "relevante à vida", (VYGOTSKY, 2001, p.133). A escrita deve ter significado para a criança, para que ela se aproprie dessa linguagem entendendo que sua aquisięão é apenas mais uma das aprendizagens necessárias para a søcialização, tal como a linguagem falada.

Para o autor, um dos grandes problemas da escrita é que o seu aprendizado não se dá naturalmente como ocorre com a linguagem oral. Segundo ele, a escrita ocupa um lugar muito pequeno na escola, em relação ao papel que ela ocupa no desenvolvimento cultural e social dos seres humanos. Conforme o autor, seria necessário que a atividade de escrita levasse o aluno a fazer o seu uso efetivo, isto é, utilizá-la da mesma maneira que ela se apresenta no mundo social.

Deste modo, é necessário, que a escrita passe a ocupar um lugar de destaque na escola como tem na sociedade, isto é, a criança precisa adquirir 
o significado social da escrita como forma de interagir e comunicar-se e o texto seria essa forma.

Nesse sentido, apresentamos, nesse artigo, uma forma diferenciada de se ensinar a linguagem escrita. Para tanto, utilizaremos a definição de Bakhtin sobre o texto, pois esse é um conceito-chave em sua teoria.

\subsection{Texto, enunciado e gêneros do discurso}

O texto escrito ou oral é definido como a realidade do pensamento e das vivências, assim, onde não há texto não há objeto de pesquisa e pensamento. De acordo com Bakhtin (2003), todo texto tem um sujeito, um autor, seja o falante, seja quem o escreve. $\mathrm{O}$ autor salienta dois elementos

que determinam o texto como enunciado: a sua intenção e a realização dessa intenção. A inter-relação dinâmica desses dois elementos é que determina o texto. Nesse sentido, o texto, é enunciado inserido na comunicação discursiva de dado campo; pois, ele é a conexão de todos os sentidos de ủm determinado campo se realizando em enunciados. Segundo o autor, há relações dialógicas entre os textos e no seu próprio interior, pois em cadá um está pressuposto um sistema universalmente aceito de signos e uma linguagem específica. Portanto, por trás de cada um está e-sistema de linguagem.--Esse sistema corresponde no texto-tudo o que é repetido e reproduzido, porém, cada texto, como enunciado, é individual, único e singular e é nessa singularidade que reside todo o seu sentido, sua intenção, ou seja, do por que ele foi criado.

A individualidade do texto é inerente ao próprio, mas só se revela numa situação e na cadeia de textos da comunicação discursiva de cada campo; conforme Bakhtin (2003), essa característica não está vinculada aos elementos repetidos do sistema da língua, mas a outros textos, a relações dialógicas e dialéticas peculiares. Essa característica do texto está ligada à autoria. A relação dialógica e dialética do texto reside no fato de ser ele 
escrito ou falado com o recurso do sistema da língua e ao mesmo tempo por ser elaborado num contexto genuíno.

Segundo o autor, o texto, diferentemente da língua enquanto sistema, nunca pode ser traduzido até o fim, pois não existe um potencial único para os mesmos. O acontecimento da vida do texto sempre se desenvolve na fronteira de duas consciências, de dois sujeitos, revela Bakhtin (2003). Nesse sentido, o diálogo é essencial no mesmo, uma vez que subjaz à complexa inter-relação do texto (objeto de estudo e reflexão) e do contexto emoldurado a ser criado no qual se realiza o pensamento cognoscitivo do leitor.

O texto é o reflexo subjetivo do mundo objetivo, pois é a expressão da consciência que reflete algo. Portanto, o objeto real de estudo, enfatiza Bakhtin (2003), deve ser o homem social inserido na sociedade que fala e se exprime por meio de signos criados por ele próprio.

Bakhtin (2003) afirma que o emprego de uma língua efetua-se sobre a forma de enunciados, sejam orais ou escritos. O termo enunciação é, também, empregado pelo autor como sinônimo de produção de discurso oral ou escrito. Conforme o autor, cada enunciado proferido é particular, mas cada campo de atividade discursiva elabora os seus tipos relativamente estáveis de enunciados, o qual denomina de gêneros do discurso.

Bakhtin (ibidem) afirma que a diversidade dos gêneros discursivos é imensa, uma vez que é inesgotável a possibilidade do uso da língua nos vários campos da atividade humana. $\mathrm{O}$ autor elucida que a lingüística que precedia a sua teoria, nunca colocou de forma adequada essa questão. Segundo ele, estudavam-se os gêneros literários e suas diferenciações no âmbito da literatura e não como determinados tipos de enunciados, que são diferentes de outros, mas que têm com estes uma natureza verbal comum.

$\mathrm{O}$ autor enfatiza a necessidade de se estudar a natureza do enunciado e a diversidade dos gêneros, tanto no aspecto geral como no particular. O desconhecimento da natureza do enunciado e a relação diferente com as 
peculiaridades das diversidades dos gêneros discursivos em qualquer campo debilitam as relações da língua com a vida.

Conforme o autor, os enunciados ou gêneros discursivos são compostos por três elementos que o constituem, são eles: estilo, estrutura composicional e conteúdo temático. Esses elementos se relacionam no todo do enunciado e são determinados pela especificidade de cada campo da comunicação ou atividade.

Sobre o estilo, o autor pontua que todo estilo está ligado ao enunciado e às formas típicas de enunciação ou gêneros do discurso; todo enunciado seja oral ou escrito é individual, podendo, portanto, refletir a individualidade do falante ou escritor, ou seja, podemos ter estilos individuais; entretanto, há determinados gêneros que não são propícios para a manifestação desse estilo individual, como por exemplo, em gêneros discursivos que requerem uma forma padronizada, tal como a linguagem do Direito. Desta forma, o estilo integra a unidade de gênero do enunciado como seu elemento, sendo, portanto, indissociável de determinadas unidades temáticas e de determinadas unidades composicionais.

Por estrutura composicional, o autor entende como a forma ou a estrutura do enunciado, isto é, determinados tipos de construção do conjunto,_como tipos de acabamento do discurso, tipos da relação do falante com o ouvinte, leitores ou parceiros, elementos gramaticais utilizados, construções de frases, utilização de determinados léxicos etc.

Com relação ao conteúdo temático o autor caracteriza como sendo o conteúdo presente na enunciação ou enunciado, que remete sempre à produção de sentidos referentes a um determinado contexto. Assim, no conteúdo temático está sempre presente a relação entre o significado e os sentidos, uma vez que para o autor o tema ultrapassa os limites da significação, ou seja, o tema é a multiplicidade de produções de sentidos.

Nesse sentido, afirma o autor, falamos por meio de determinados gêneros do discurso, isto é, todos os nossos enunciados possuem formas 
relativamente estáveis e típicas de construção do todo do enunciado. Segundo o autor, falamos sob o enfoque de determinados gêneros ainda que o desconheçamos em termos teóricos, pois os gêneros nos são dados quase da mesma maneira que nos apropriamos da língua materna. $\mathrm{O}$ conhecimento da língua materna ressalta Bakhtin (ibidem), se dá pela forma de enunciações concretas que ouvimos e reproduzimos na comunicação viva com as pessoas que nos rodeiam, assim, as formas da língua e as formas típicas de enunciados ou gêneros do discurso, chegam à nossa consciência em conjunto. Todavia, salienta o autor, é preciso dominar bem os gêneros para empregá-los livremente.

\section{Aspectos metodológicos da pesquisa}

Para que fosse possível atingirmos o objetivo da pesquisa aqui relatada, que foi verificar, identificar e analisar os conhecimentos sobre a língua gerados por meio de uma de parceria entre leitor e escritor, tendo em vista a formação de um escritor consciente do discurso produzido, tivemos que fazer uma intervenção com quatro crianças de uma segunda-série dó ensino fundamental no período de um semestre, totalizando 12 encontros. Nesses encontros, fazíamos a escolha antecipada de temas a serem dialogadōs,-redigidos e reescritos, enfocando diferentes tipos de gêneros discursivos, sendo eles: texto de opinião, fábula, reconto, narrativa, receita, carta, descrição, diálogo e texto livre.

Como procedimentos metodológicos, cada encontro constava de quatro momentos: diálogos do tema proposto, produção de texto escrito individual, parceria entre leitor e escritor, e reescrita do texto. Para que pudéssemos capturar todo o contexto, utilizamos os seguintes procedimentos técnicos de coletas de dados: fitas de áudio e documentos escritos dos alunos (textos). 
Os dados foram analisados qualitativamente de acordo com os objetivos propostos, a fim de responder a questão de pesquisa proposta: quais os conhecimentos da língua gerados por meio de um processo de parceria entre leitor e escritor?

Desta forma, analisamos as produções individuais dos sujeitos (o texto), o diálogo oralizado entre leitor e escritor propiciado pela parceria e quais as influências desse processo dialógico presente no texto escrito após a parceria entre leitor-escritor, o que evidenciaria os conhecimentos sobre a língua gerados durante esse processo. Contudo, tal análise (dos conhecimentos sobre a língua gerados) ocorreu por meio do processo de produção textual, ou seja, não analisamos apenas o produto dessa interação, mas o processo dessa construção no período de coleta de dados. Para análise dos conteúdos da língua gerados categorizamos os dados em relação aos seguintes aspectos (categorias essas que foram evidenciadas pelas próprias crianças): coerência quanto ao conteúdo temático; aquisição de elementọs que fazem parte da estrutura composicional de determinados gêneros discursivos, elementos esses que constituem o estilo do gênero; identificação dos diversos gêneros discursivos; consideração do leitor na produção textual (significado e sentidos); aspectos gramaticais: pontuação, ortografia e concordância.

Para apreender toda a realidade, em um primeiro momento, relacionamos o gênero textual trabalhado e o contexto de produção, com as influências da parceria leitor-escritor; num segundo momento, verificamos os conhecimentos da língua gerados como um todo, durante o processo de parceria.

\section{Resultados da pesquisa}

Os resultados da pesquisa aqui relatada revelam que o discurso oral é mais rico que o texto escrito, pois a leitura do mundo aparece no discurso 
oral sob a forma de relações proporcionadas pelo contexto, tal como evidenciou Vygotsky (1993) e Bakhtin (2003); já o texto escrito apresentava pistas do contexto que foi anteriormente oralizado, o que possibilitou a revelação das condições e contexto de produção das crianças; contudo, essas ainda não apresentavam o domínio dos gêneros e dos significados das palavras, o que não permitiria a um leitor que não tivesse participado do contexto, por vezes, entendê-lo.

Todavia, durante o processo de intervenção e de parceria, foi possível notarmos uma melhora qualitativa em termos de a criança deixar as pistas necessárias ao leitor, para que esse chegasse o mais próximo possível da significação a qual quisera deixar o autor no texto. Geraldi (2003) acentua essa aprendizagem como um dos aspectos fundamentais do produtor e leitor textual.

Os dados nos mostram ainda que, na parceria, as crianças privilegiavam os aspectos gramaticais e a forma do texto, por ser essa a preocupação deles naquele momento. Tal fato pode estar relacionado às enunciações das crianças que evidenciavam pelo diálogo oralizado, que a professora da sala de aula trabalhava com a construção de frases, privilegiando os aspectos gramaticais da língua. Nesta pesquisa, apenas um dos sujeitos privilegiava a coerência como necessidade para compreensão do texto escrito, enfatizando que o leitor não conseguiria entender devido à falta de palavras, de sentido. A preocupação dessa criança com esse aspecto nos permite inferir que seja pelo fato dela já ter se apropriado de outras questões da língua, como ortografia, acentuação, etc.

Quanto aos aspectos metodológicos, a análise desse processo evidenciou que a parceria permite a aprendizagem de novos pontos de vista, devido ao diálogo, a melhora qualitativa do texto escrito e fomentos da formação da consciência discursiva. Com relação à melhora qualitativa do texto e a formação da consciência discursiva verificamos que no processo de produção, os sujeitos começaram a se conscientizar de alguns aspectos do 
texto, tais como: repetição de idéias ou várias idéias no texto sem continuidade, consciência de elementos da estrutura composicional, aspectos estruturais que compõem alguns gêneros discursivos, como o estilo do gênero e, por fim, o leitor inserido no texto já na sua produção.

Para concluir, identificamos que a mediação intencional nas relações de ensino-aprendizagem propiciada pela figura do professor, é fundamental no processo de aprendizagem da língua, pois é ele que faz com que os alunos reflitam sobre o texto, sobre o papel do leitor e do escritor no processo de produção textual. A mediação intencional caracteriza-se como a principal influência para a formação da consciência discursiva, devido ao planejamento e organização das atividades que envolvem a intervenção. Assim sendo, o trabalho educativo desenvolvido pelo professor é decisivo e indispensável, uma vez que exige uma maior elaboração do conhecimento, todavia esse trabalho intencional deve ainda, ser entendido como uma mediação do processo de transformação das relações sociais.

\section{Considerações finais}

Levando em consideração os objetivos propostos na pesquisa realizada, identificamos que quando havia diretividade da ação (na reescrita), por meio da mediação intencional, as crianças conseguiam uma melhora qualitativa no texto escrito, em relação ao texto inicial (escrita antes da parceria). Isso se deve ao que Vygotsky (1995) evidencia sobre a necessidade de meios externos como auxiliadores das atividades das crianças, já que elas ainda não possuem um domínio voluntário dos processos internos.

Esse dado nos leva a verificar que o processo é longo e não é pontual, e que o ato de escrever é uma atividade que se desenvolve por meio de rotas diferenciadas, pois no momento de se produzir um texto a criança está operando com a memória, com a criatividade, com a emoção, com a 
semântica, com a gramática, com a ortografia, etc. Conforme Leontiev, as atividades humanas diferem-se por diversas razões: vias de realização, tensão emocional, mas, o fundamental que distingue uma atividade de outra é seu objeto, isto é, "o objeto da atividade é seu motivo real" (LEONTIEV, 1983, p.83). Por isso, na reescrita textual, os aspectos evidenciados e direcionados pela parceria faziam com que houvesse um detalhamento maior e uma atenção pormenorizada às questões evidenciadas pelas próprias crianças, aspectos esses que foram categorias por nós escolhidas para serem analisadas.

A análise nos permitiu verificar que o texto oralizado é mais rico que o texto escrito. Isso se deve também ao que Vygotsky (1993) salienta sobre o processo da atividade escrita. Wertsch (1995) ao dissertar sobre o processo de descontextualização dos instrumentos de mediação revela que a organização lingüística depende do contexto, sendo esta a primeira forma de contato da criança com o signo. Por outro lado, algumas funções do sígno refletem o aspecto descontextualizado da organização lingüística, como a atividade da escrita.

De acordo com Vygotsky (2001), o desenvolvimento dos conceitos científicos tem um significado primordial para a evolução dos processos psicológicos superiores, porque estes conceitos implicam necessariamente que se realizem de maneira consciente. Contrariamente às formas inicias dependentes de contexto que caracterizam os conceitos espontâneos, a descontextualização inerente aos conceitos científicos, permite a formação dos processos psicológicos superiores. $\mathrm{Na}$ explicação do autor, sobre as funções psicológicas superiores, os conceitos científicos são os que permitem aos seres humanos realizar a atividade mental independente do contexto concreto, quer dizer, representam o ponto final da descontextualização dos instrumentos de mediação. Entretanto, na teoria proposta pelo autor, acerca do desenvolvimento dos conceitos, a apropriação dos conhecimentos científicos só ocorre no período posterior à adolescência. 
Isso nos leva a inferir que a criança necessita do contexto concreto para realizar as suas atividades de modo significativo.

Diante do exposto, se a consciência é formada por essas significações, a iniciação da criança na escrita deve ser por meio de atividades que remetam ao contexto. Os dados referentes à influência do gênero na aquisição da escrita, seria a prova das palavras de Vygotsky. O autor utiliza o conceito de atividade já em seus primeiros escritos e sugere que a atividade socialmente significativa é o princípio explicativo da consciência, ou seja, a consciência é construída de fora para dentro por meio das relações sociais.

Verificamos que os gêneros trabalhados que remetiam ao reconto, ao relato de uma situação vivenciada, ou a descrição de um objeto ou de uma pessoa, fizeram com que as crianças cometessem menores desvios em relação às categorias sobre a língua analisadas, como pontuação, ortógrafia, coesão, coerência, acentuação e concordância, pois o próprio gênero é um meio externo auxiliador, diferente do texto de opinião ou do texto livre. Entretanto, não foi o objetivo desse trabalho verificar a influência dos gêneros discursivos na apropriação da escrita por crianças recém alfabetizadas; contudo, essa é uma questão que merece ser discutida por futuras pesquisas.

Os dados obtidos nesse trabalho salientam que, na parceria, as crianças em período de apropriação da língua (alfabetização) privilegiaram os aspectos gramaticais e a forma do texto, sendo, num momento posterior, a sua preocupação com a coerência textual como necessidade para a compreensão do texto escrito, ou seja, nesta pesquisa verificamos que a preocupação das crianças recém- alfabetizadas se circunscreve às questões relacionadas à ortografia, pontuação, acentuação, se devendo, sobretudo, ao trabalho desenvolvido pelos professores em sala de aula. Nesse sentido, intuímos que o processo de aquisição da escrita pela criança se daria em três diferentes níveis. $\mathrm{O}$ primeiro seria a apropriação do sistema alfabético, tal 
como evidenciou Ferreiro e Teberosky (1985); o segundo estaria relacionado às normas ortográficas da língua (FERREIRO, 2000; MORAIS 2000 e 2003); o terceiro nível, poderia estar associado às questões semânticas e à estrutura do texto escrito, como pontuação e estrutura composicional. A inferência sobre essas questões está baseada nos sujeitos aqui analisados e na experiência prática como docentes em salas de alfabetização ou pós-alfabetização. No entanto, é necessário um estudo mais detalhado sobre essas questões de maneira a verificar se é um processo psicogenético ou cultural, uma vez que esses dados podem estar associados à prática dos professores nas salas de aulas após a apropriação da escrita alfabética pela criança:

No que concerne à análise do processo de parceria, a confrontação entre leitor-escritor, permiti às crianças a aprendizagem de novos pontos de vista, a ouvir e a falar, pois o contato com outras leituras de mundo permitem a elas que visualizem idéias possíveis para a construção de textos, tal como observamos no diálogo oralizado e nas pistas contidas no texto escrito dos sujeitos dessa pesquisa.

Com relação à atividade de leitura, proporcionada pela parceria, verificamos dois enfoques dados pelas crianças; sendo um relacionado às questões_da língua (gramática, ortografia, pontuação, etc); e, outro, relacionado ao sentido textual. De acordo com Vygotsky (1991), os diferentes tipos de realização da leitura, ou seja, uma para a compreensão de sentido e, outra, para a apreensão da correta notação gráfica, se deve à maneira pela qual a leitura é realizada, portanto, verificar o que há de errado no texto das crianças depende estritamente da intencionalidade no ato de ler. Tal fato nos leva a verificar que as crianças desta pesquisa, por serem crianças de uma segunda série e que haviam acabado de se apropriar do sistema de escrita alfabética, elas estavam ainda, direcionadas aos aspectos da língua, muito mais que do sentido do texto. 
Portanto, a formação da consciência discursiva nos produtores de textos é um processo demorado e, por essa razão, é fundamental a intencionalidade da ação nas relações de ensino-aprendizagem. Ter a consciência do papel do signo e da linguagem, enquanto constituídoras das funções mentais superiores é essencial para que propiciemos um ensino de qualidade, uma vez que somos profissionais da área do ensino da língua. Vygotsky (1991) e Bakhtin (1995) definem a consciência como conhecimento partilhado, que ocorre somente na realização social, de forma que a consciência individual só pode existir a partir de uma consciência social que tem na língua seu substrato real, dessa forma é essencial que os professores, como mediadores intencionais do processo de ensinoaprendizagem, tenham a consciência do que é a linguagem e a apropriação da língua.

\section{Referências bibliográficas}

ARAÚJO, C. L. S.. O Esvaziamento da atividade mediadora do professor no processo de apropriação-objetivação de conhecimentos pelos alunos. UNESP/ Marília, 2000.

BAKHTIN, M.. Marxismo e Filosofia da Linguagem. São Pauto: Ed. Hucitec, 1995.

2003.

Estética da Criação Verbal. São Paulo: Martins Fontes,

FERREIRO, E. \& TEBEROSKY, A.. Psicogênese da língua escrita. Trad. de Diana Myriana Lichtentein, Liana Di Marco e Mário Corso- Porto Alegre: Artes Médicas, 1985.

FREIRE, P.; MACEDO, D.. Alfabetização: leitura do mundo, leitura da palavra. São Paulo: Paz e Terra, 1990.

GERALDI, J. W. Portos de passagem. São Paulo: Martins Fontes, 2003.

KRAPIVINE, V.. Que é o materialismo dialético? Moscou: Edições Progresso, 1996. 
LEONTIEV, A. N.. Atividade, consciência e personalidade. In: http://www.livrosgratis.com.br/download_livro_11101/atividade,_conscienc ia_e_personalidade

LURIA, A. R.. Pensamento e linguagem: as últimas conferências de Luria. Rio Grande do Sul : ARTMED, 2001.

MARX, K.. Contribuição para a crítica da economia política, 1859. São Paulo: Ed. Abril. Coleção os Pensadores, volume 35, Ed. Abril.

A ideologia alemã. Rio de Janeiro : Zahar Editores, 1977.

VYGOTSKY, L.S.. Obras escogidas. Madri: Visor, Tomo II, 1993.

Obras Escogidas. Madri: Visor Tomo II, 199.5.

A construção do pensamento e da linguagem. São Paulo Ed.

Martins Fontes, 2001.

WERTSCH, J. V.. Vygotsky y la formacion social de la mente. Barcelona- Buenos Aires- México: Ediciones Paidós, 1995.

ZUIN, P. B.. Linguagem, sujeito e consciência - um enfoque materialista. In: MIOTELLO, V. (org.). Veredas bakhtinianas. São Carlos: Pedro \& João Editores, 2006.

\section{Autoras:}

Dra. Poliana Bruno Zuin

Professora e Coordenadora do Curso de Pedagogia da Faculdade de Tecnologia, Ciências e Educação - FATECE e Professora da Universidade Aberta do Brasil - UAB- UFSCar

Contato: polianazuin@ hotmail.com

Claudia Raimundo Reyes

Professora da UFSCar

Contato: clreyes@power.ufscar.br 
Texto recebido em maio de 2011.

Texto aprovado para publicação em janeiro de 2012.

\section{Como citar este texto:}

ZUIN, P. B.; REYS, C.R.. As influências de uma parceria entre leitor e escrito na produçã de textos. Revista Acolhendo a alfabetização nos países de língua portuguesa, Brasil, São Paulo, volume 1, no. 12, p. 24 49, Mar. 2012. Disponível em: <http://www.acoalfaplp.net>.

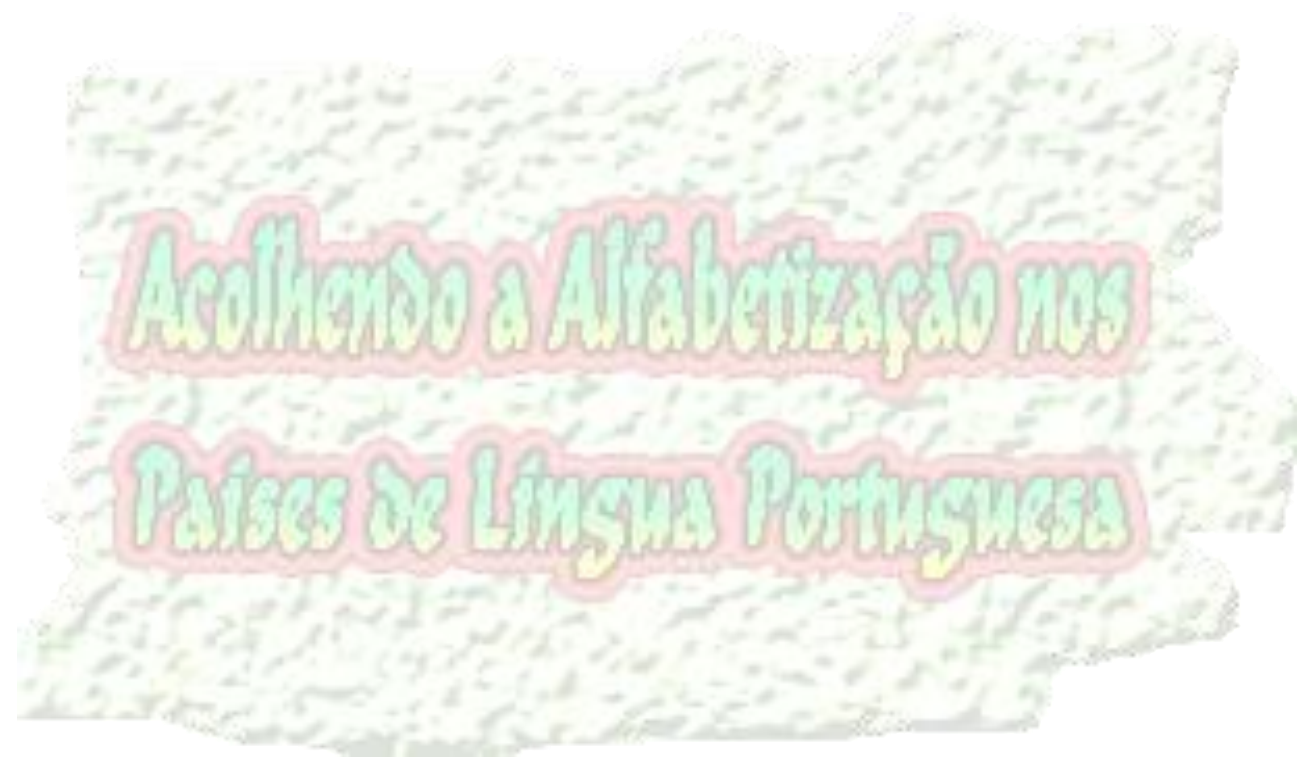

